\title{
Testing for Single Bubble Episode in the Nigerian Stock Market: An Empirical Investigation
}

\begin{abstract}
Jamilu Iliyasu ${ }^{1}$ and Ndayezhin D. Saba ${ }^{2}$
This study evaluates a single bubble episode in the Nigerian Stock Exchange (NSE) by utilizing monthly data on nominal and real all-share index (ASI) from January 2010 to December 2017. Analysis of data based on Sup Augmented Dickey-Fuller (SADF) test for bubble detection suggests non-existence of a bubble in the NSE between 2010 and 2017. Though there is an indication of one explosive episode in September 2011 at which the DickeyFuller statistic lied above the critical values sequence line. However, it is not a bubble but a short deviation from trend. The study also estimates a time-varying long memory parameter, using a fractionally-integrated autoregressive model to check the robustness of the SADF test and it provided further evidence on the absence of a bubble. These findings showed that the behaviour of stock prices is not driven by a bubble in the Nigerian Stock Exchange (NSE). The study, therefore recommends a time-to-time bubble diagnostic check on the exchange so that symptoms of a bubble can be early detected and managed to avoid losses that may result from the bust.
\end{abstract}

Keywords: Bubble, Date-Stamping, Fractional Integration, Long Memory, NSE, Sup-ADF

JEL Classification: G12.

DOI: $10.33429 /$ Cjas.10119.2/6

\subsection{Introduction}

Identifying and date-stamping financial bubbles or asset price bubbles in real time has attracted significant research attention among financial economists. It is equally a subject of concern for policy makers (both monetary authorities and fiscal regulators), including key financial regulators. With the historical and empirical evidences (Markus and Isabel, 2015) and as global capital markets continue to expand in scale and scope, speculative bubbles in asset prices have been recognized

\footnotetext{
${ }^{1}$ Corresponding author;Department of Economics, Ahmadu Bello University- Zaria, Nigeria. Email: jamnashuha@gmail.com, Tel: +2347033986268

${ }^{2}$ Department of Economics, Ahmadu Bello University- Zaria, Nigeria. Email: isand88@yahoo.com, Tel: +2348039114466
} 
by many economists and policymakers, as an important source of macroeconomic instability, with the bursting of some large bubble, often pointed to as a key factor behind many financial crises. They are equally useful as warning alerts in surveillance strategies conducted by central banks and fiscal regulators with real-time data (Philips, et al. 2015). Bubble in asset price, also known as irrational exuberance, is formed when assets prices are no longer justified by their fundamentals (Porras, 2016) and fundamental implies set of variables that drive changes in the value of the underlying asset in question. Historically, stock prices experienced impressive growth that cannot be explained by growth in fundamentals. For instance, the NASDAQ index rose to a historical high of 5,048.62 points on March 10, 2000, from 329.80 on October 31, 1990 (Phillips, et al., 2011; Markus and Isabel 2015). This led to a debate amongst central bankers and academics in the United States, whether growth is justified by growth in economic fundamentals or irrational exuberance.

For example, observing unprecedented growth, the then Chairman of the Federal Reserve Board, Alan Greenspan on December 5, 1996, expressed concern over the existence of "irrational exuberance" in the American stock market (ASM) and a day following the remark, stock markets all over the world plummeted (Phillips, et al., 2011). This is the DotCom bubble that bust in the early 2000s, wiping out about $\$ 8$ trillion worth of shareholder wealth (Porras, 2016) and a few years later a bubble in the real estate market triggered the 2007/2008 Global financial crisis that eroded about $\$ 19.2$ trillion worth of household wealth in the United State (Porras, 2016). The effects of the crisis were not limited to United State alone, it spread all over the world, consuming about $\$ 5$ trillion in global gross domestic product (GDP) and over $\$ 25$ trillion in stock market losses (Sornette, 2013).

In Nigeria, for example, the Nigerian capital market experienced unprecedented growth from 2003 to 2007 during which market capitalization of the Nigerian Stock Exchange (NSE) grew by over 66 per cent per annum (Gwarzo, 2016), all-shareindex (ASI) grew by 380.3 per cent from February 2003 to February 2008 (CBN, 2015). Almudhaf (2017) in his study of irrational exuberance found empirical evidence that is consistent with speculative bubbles within this period. The ASI later 
loss about 67.67 per cent of its value from March 2008 to Friday, April 27, 2009 (Kighir, 2009) while market capitalisation, after reaching its peak of N12.6 trillion in March 2008, lost about 70 per cent of its value within the same year (Gwarzo, 2016). After the crash in 2009, the Central Bank of Nigeria (CBN) instituted series of policy measures in order to stabilise prices and promote sound financial system. The Bank speed up recovery from the effects of the crash and safeguard the market against future occurrences of another crash. These policies included:a reduction in the monetary policy rate (MPR) from 10.25 per cent to 9.75 per cent and further to 8.0 per cent; reduction in the cash reserve requirement (CRR) from 4 per cent to 2 per cent. These measures are apt because bubbles have the tendency of complicating the task of maintaining price stability, by damaging the traditional channels of monetary policy and increasing risk-taking by banks.

Few months after the recovery from August 2016 recession, the ASI rose by 33.33 per cent from 25,516.34 on March 31, 2017, to 34, 020.37 on July 21, 2017, while the market capitalisation rose by 32.84 per cent from N8.83 trillion to N11.73 trillion. Given these, Monetary Policy Committee (MPC) of CBN expressed concern over what it described as "seeming bubble" in the NSE after its meeting in July 2017. Three days after the remark, the market lost N2.7 billion of the market capitalisation in reaction to the remark. In addition, Garba in the communique No. 116 of CBN in September 2017 expressed similar concern that "it is worthy of note that the stock market is in its third bubble since 2006: 2006 -2008; 2012 2014 and from April 2017" p.34. Despite these concerns, coupled with the significance of identifying and date-stamping stock market bubble, it is surprising that relatively little efforts have been made in identifying and date-stamping financial bubble in Nigeria especially after the rebound from 2008 Global financial crisis (GFC).

In this study, an attempt is made to contribute to the existing empirical literature on financial bubble by investigating the existence of bubble in the NSE after the rebound from the effect of 2009 economic recession and 2008 GFC, and to also date-stamp financial bubble in the NSE within the same period, to provide empirical justification for the MPC remark of "seeming bubble" in the NSE. We follow 
the contesting methodological issues in the literature, that suggest co-integration as a less effective methodology in identifying periodically collapsing bubble and date-stamping of asset price bubbles which most of the reviewed studies in Nigeria applied (Chukwuma-Agu and Agu, 2009; Agu and Chukwuma-Agu, 2010; Njiforti and Chidiogo, 2010; and Mike and Abraham, 2015). We add to these studies by providing bubble diagnostic check on the NSE after its rebound from the effect of 2008 GFC (2010 - 2017) which was not covered by the previous studies. This study follows the leads of Philips, et al. (2011) by applying SADF methodology, which is more effective in both detecting and date-stamping single episode of asset price bubble (rational, intrinsic, periodically collapsing bubble among others) which to the best of our knowledge, has not been applied to the NSE data.

Following this section, we structured the rest of the papers as follows; Section 2 reviewed the related literature on asset price bubble. Section 3 outlined the methodology which included the framework of analysis, estimation technique, model specification, and sources of data used for the study. In Section 4, the result is presented and discussed. Section 5 concluded the paper.

\subsection{Literature Review}

This section presents theories on assets price bubble formation and empirical studies on detecting the occurrence as well as date stamping of an assets price bubble in stock markets and other markets.

\subsection{Theoretical Literature}

Efficient Market Hypothesis (EMH) is one of the most famous roots upon which many asset pricing models stand. It states that the market price of an asset in an efficient market reflects the best assessment of its value at a given time (Porras, 2017). It further added that the current price of an asset reflects (incorporates) both the current and future expected information that needs to be known about the asset as well as its fundamentals (set of variables that drives changes in the value of the underlying asset in question). One implication of EMH is that it is impossible or difficult for an investor to beat the market on a risk-adjusted basis 
or through arbitrage, consistently because the prices already reflect the entire information available relative to the asset in question (Porras, 2016/2017). By this theory $(\mathrm{EMH})$, for example, in stock markets, stock prices follow a random walk and are unpredictable; thus, only unanticipated new information can change the underlying asset valuations (Shiller, 2015). This is because, theoretically, in an efficient market, information is costless; investors are rational and have homogenous expectations as well as equal access to all available information. Thus, assets prices reflect their fundamentals and cannot deviate from their equilibrium value, as such bubbles cannot occur since they are deviations from equilibrium (Diba \& Grossman, 1988; Matthias, 1997; McQueen \& Thorley, 1994; Fama, 1965).

Conversely, Blanchard \& Watson (1982) and later Diba \& Grossman (1988) developed a theory of asset price bubble which is known as a rational bubble; that does not violate the rational expectations hypothesis and is consistent with the EMH (Chen, et al., 2015). For example, McQueen and Thorley (1994) explained that the rational bubble theory allows stock prices to deviate from their fundamental value without assuming irrational investors. They are generated from sustained expectations of higher prices without any changes in the stock fundamentals (Matthias, 1997). In addition, rational bubble as argued by Diba and Grossman (1988) can only start at the first date of trading the asset (the Inception Hypothesis) and at the same time, the agents in the market know the asset is overvalued but willing to pay for the premium in expectation of future price increase.

The theoretical work of Diba and Grossman (1988) on the rational bubble led to other theoretical explanations on asset bubble. For example, the proponents of behavioural finance theory argued that markets are not always efficient and agents (or investors) not always rational, as posited by EMH. Thus, it is very possible for assets prices to deviate from their fundamental value, which may result in overvaluation or asset price bubble formation. Behavioral finance proponents also see assets price bubbles as price increase not supported by fundamentals which emanate from psychological contagion. In order words, bubbles are essentially delicate social-psychological events (Shiller, 2015). In an inefficient market which is characterized by low transparency and asymmetry of information, participants 
(investors) sometimes follow herding behaviour; by discarding their private signals and resort to imitating other investors' trading strategies.

Herding behaviour or imitation leads to positive feedbacks in the market (Zhoua \& Sornette, 2009). Positive feedback occurs when an increase in price begot another increase and at the same time increase in the number of purchases. That is, action leads to consequences which themselves reinforce the action and so on (in this situation the law of demand does not hold). The implication for stock prices, however, is that they increase and heighten the expectations for higher future prices among investors (Zhoua \& Sornette, 2009). Through positive feedback, prices usually rose beyond fundamental justification and induce higher probability of bubble occurrence in the market, as the price is pushed farther away from equilibrium. When the bubble matures and reaches its peak level, any little signal suggesting the current price may not be sustainable but trigger negative feedback (for example, increase in federal fund rate, repo rate or monetary policy rate in the case of US, UK and Nigeria respectively). Negative feedback occurs when a decrease in price keeps inducing further rounds of price decreases. As the trigger event takes effect (an event that shows future prospect of prices is gloomy and leading to pessimistic expectations), fire selling (when investors start selling to minimise losses) results to a scenario where prices keep falling and more quantities of the asset are offered for sale. This situation explains most of the stock market booms and crashes. For example, the Dotcom bubble in 2000, the real estate bubble in 2006, and the Nigerian stock market bubble in 2007.

\subsection{Empirical Literature}

After the effects of the 2008 Global financial crisis spread its tentacles over most African economies, it spurs interest among central bankers and academia on empirical studies on bubble occurrence within their stock markets. In Nigeria, such empirical works include; Chukwuma-Agu and Agu (2009); Agu and ChukwumaAgu (2010); Njiforti and Chidiogo (2010); Mike and Abraham (2015); and Almudhaf (2017). Njiforti and Chidiogo (2010) conducted an empirical investigation on the presence of bubble among listed banks and insurance companies stock prices in the NSE. The study used daily data on price-dividend ratio, share price, and 
dividend from 2008Q01-2009Q04 for Access Bank, Guarantee Trust Bank, United Bank for Africa, Unity Bank, Aliko Insurance, Cornerstone Insurance, LASACO Insurance, Law Union Insurance, and Niger Insurance. Using standard unit root and cointegration tests, the study found no co-integrating relation among share prices, price-dividend ratio, and dividend in most of the banks and insurance companies and then concluded that the behaviour of prices during the study period was consistent with bubble behaviour.

Similarly, Agu and Chukwuma-Agu (2010) investigated the role of market fundamentals and bubble in stock pricing, as well as market movement in the NSE, to provide empirical evidence on the causes of the crisis in 2008. Using quarterly data on All-share index (ASI), exchange rate, interest rate, output growth and inflation rate from 1990Q1 to 2007Q4 and co-integration technique. The study found no co-integrating relation between all-share index and the market fundamentals. It then concluded that share prices were not driven by fundamentals and price-setting dominated NSE during the study period. As already established, if assets price and its fundamentals are not co-integrated, it implies the presence of a bubble and this is exactly what the study concludes. In addition, Nwidobie (2015) conducted an empirical investigation of the effects of macroeconomic variables on share prices in the NSE. The study employed annual data spanning1985 to 2013 on the all-share index, consumer price index, interest rate, and productivity index. Using ordinary least square technique, the study established negative relationships between the all-Share index and macroeconomic variables (inflation, interest rate, and national productivity) and found no co-integrating relation between the allshare index and the macroeconomic variables. The study concluded that there is no significant positive relationship between the macroeconomic variables and stock prices in the NSE. This study indirectly tested for a bubble, though not quite explicit in the objective of the study and the no co-integrating relationship revealed evidence of bubbles in the NSE during the period.

However, periodically collapsing bubble exhibit nonlinear behaviour, which looks like mean reversion and could escape detection by the co-integration test. Another important implication of this bubble detection methodology is that it lacks effec- 
tive dating of the bubbles episodes, that is, it only tells that bubbles are present. But much more important is the time of occurrence so that causes can be identified and timely action can be rightly taken. The Phillips, et al., (2015) test is acknowledged as the most effective bubble detection and date-stamping methodology that outperforms comparable approaches in terms of size and power in case of multiple bubble episodes within a sample (Brunnermeie, et al., 2018). To achieve effective detection and dating of bubbles within frontier stock markets of Africa, Almudhaf (2017) conducted an empirical investigation of bubbles in African frontier stock markets of Botswana, Egypt, Morocco, Ghana, Kenya, Nigeria, Mauritius, and Tunisia. The study used monthly data on price-dividend ratio from 1900 to 2016 for Botswana, 1997 to 2008 for Egypt, 1997 to 2008 for Ghana, 1997 to 2008 for Kenya, 1988 to 2008 for Nigeria, 1997 to 2008 for Mauritius, 1997 to 2008 for Morocco and 1997 to 2008 for Tunisia. Using the Phillips, et al., (2015) methodology known as Generalised Sup Augmented Dickey-Fuller (GSADF) test, the study established evidence of multiple speculative bubbles in Botswana, Egypt, Ghana, Kenya, Nigeria, and Tunisia. For NSE, four episodes of speculative bubbles were identified including the 2007 bubble. The first three bubbles were short-lived from February to March 1996, March to May 1997, and May to June 2004. The last bubble began in March 2007 and ended in July 2007. In contrast, when one suspects single bubble, Phillips, $\mathrm{Wu}$ and $\mathrm{Yu}$ (PWY) test is most effective methodology, as simulation has revealed (Phillips, et al.,2015; Balcilar, et al., 2016).

In summary, the reviewed literature suggests four keys issues. First, most of the empirical literature in bubble detection in Nigeria used cointegration technique, which is less effective in detecting periodically collapsing bubbles. Secondly, the empirical studies utilised annual and quarterly data with the exception of Njifforti and Chodiogo (2010) that used daily data but employed cointegration analysis. Thirdly, the PWY (SADF) test, which is acknowledged to be more effective in detecting and date-stamping single bubble episode, to the best of our knowledge, has not been applied to NSE data. The work of Almudhaf (2017), which applied GSADF test for African frontier stock markets of Botswana, Egypt, Morocco, Ghana, Kenya, Nigeria, Mauritius, and Tunisia, is a cross country study and not specific to NSE. Finally, none of these studies extend to 2017, which left the be- 
haviour of stock prices unexplained regarding the occurrence of a bubble after the rebound from the 2008 Global financial crisis. These provide a gap in the empirical literature of bubble detection and date-stamping in Nigeria, which this study attempts to fill.

\subsection{Data and Methodology}

Phillips et al. (2015) test is the most effective multiple bubbles detection methodology and outperforms comparable approaches (for example, regime switching, quintile regime switching, variance bound test, west test, unit root and cointegration tests) in terms of size and power in case of multiple bubble episodes within a sample (Brunnermeie, et al., 2018) and it detects both rational and periodicallycollapsing bubbles. But when one suspects single bubble episode in the data, Phillips, et al., (2015) through simulation show that the Phillips et al., (2011) (SADF) test is most effective, which has been used in Phillips, et al.,(2011) to date-stamp irrational exuberance in NASDAQ index (Phillips, et al., 2015). Following MPC's remark of "seeming bubble" in NSE, this research suspects single bubble episode. This study, therefore, applied Phillips, et al.,(2011) methodology to date-stamp the occurrence of a single bubble episode in the NSE.

\subsection{Data Sources and Description}

The study employed monthly data on all-share index (ASI), consumer price index (CPI), from Central Bank of Nigeria Statistical Bulletin, spanning January 2010 to December 2017. Following Phillips, et al. (2011) and Phillips, et al. (2015), we used the CPI to convert the nominal ASI into real ASI, this to express the stock prices in real terms and to allow for effective comparison of the prices in the NSE.

\subsection{Estimation Technique and Model Specification}

The Phillips, et al. (2011) test also known as SADF test is Rolling Right Tailed Augmented Dickey-Fuller (RTADF) type of a forward recursive regression and it aims at finding explosive behaviour that might emanate from the price $\left(p_{t}\right)$ in Equation 4, in the presence of a bubble. Following Deng, et al. (2017) we specify the rolling window RTADF based on the autoregressive specification: 


$$
\Delta y_{t}=\alpha+\beta y_{t-1}+\sum_{i=1}^{k} \gamma_{i} \Delta y_{t-i}+\varepsilon_{t}
$$

where $y_{t}$ is real NSE-ASI (ASI corrected for inflation), $\alpha$ is the intercept, $k$ is the maximum number of lags, $\gamma_{i}$ for $i=1, \ldots, k$ are the differenced lags coefficients and $\varepsilon_{t}$ is the error term. Since the Phillips, et al. (2011) test is based on the right-tail version of standard ADF unit root test, the null hypothesis is of a unit root and the alternative is of a mildly explosive autoregressive coefficient against the standard ADF, where the alternative hypothesis is stationary. The hypothesis is formally stated as:

$$
\begin{aligned}
& H_{0}: \beta=1 \\
& H_{1}: \beta>0
\end{aligned}
$$

Thus, testing for a bubble involves searching for explosive behaviour in the price series. Where in forward recursive regressions, Equation (5) is estimated repeatedly, using subsets of the sample data incremented by one observation at each pass (Phillips, et al., 2011). The Dickey-Fuller (DF) statistic and sup ADF (SADF) that is highest $\mathrm{ADF}$ statistic, are generated from equation (5) in forward expanding sample sequence (Phillips, et al., Wu, \& Yu, 2011; Yiu, et al., 2012; Itamar, et al., 2014; Phillips, et al., 2015).

However, in order to identify the beginning and ending date of a bubble, the recursive DF statistic is matched against the critical value sequence generated by Monte Carlo simulation with 1000 replication. That is the beginning of a bubble is dated as the first recursion for which the value of the DF statistic of estimated $\beta$ is equal to or larger than the right side critical value, and the end date is identified as the first subsequent recursion for which the DF statistic drops back to or below the critical value (Yiu, et al., 2012). Implementing the rolling ADF for Equation $(5)$, requires a minimum window size $\left(r_{0}\right)$ and needs to be chosen according to the number of observations $(T)$ in the sample period. Again, if $T$ is small, $r_{0}$ needs to be large enough to ensure sufficient observations for adequate initial estimation, if $T$ is large, $r_{0}$ can be set to be a smaller number so that the test does not miss any opportunity to detect an early explosive episode (Phillips, et al., 2015). Based on simulation, Phillips, et al., (2015) recommended a rule for choosing with func- 
tional form $r_{0}=0.01+1.8 / \sqrt{T}$. Duration of bubble is set as $L=\log (T)=L T=$ $\log (84) \approx 2$ months. This requirement helps to exclude short-lived deviation from trend in the fitted autoregressive coefficient $\beta$.

\subsection{Testing Procedure and Checks for Robustness}

The testing procedure in this study is carried out in three stages. First, we applied the SADF test to ascertain the presence (or absence) of a bubble. Second, we performed BSADF test to date-stamp the bubbles. Finally, ADF, Right Tail ADF (RTADF) test and fractionally-integrated autoregression were carried out as check for robustness of SADF test (Chang, et al., 2016; and Phillips, et al., 2011).

\subsection{Theoretical Framework of Analysis}

The present value model (PVM) posited that value of an asset depends on the expected future cash flows (dividends), since ownership of an asset gives a right on future expected cash flows or dividend (Krause, 2001). Then, the current price of the asset becomes;

$$
P_{t}=\frac{1}{1+r_{t+1}} E_{t}\left[D_{t+1}+P_{t+1}\right]
$$

where $P_{t}$ is the asset price (such as stock price) at time $t, D_{t+1}$ is the future expected cash flow (such as dividend) and $\mathrm{r}$ is the discount rate $(r>0)$. Solving Equation (1) forward for $k$ periods results in;

$$
P_{t}=\sum_{j=1}^{k}\left[\prod_{j=1}^{i} \frac{1}{\left(1+r_{t+j}\right)}\right] D_{t+j}+\left[\prod_{j=1}^{k} \frac{1}{\left(1+r_{t+j}\right)}\right] P_{t+k}
$$

If we assume the asset price to grow at a lower rate than, . Then, the last term converges to zero, such that:

$$
\lim _{x \rightarrow \infty}\left[\prod_{j=1}^{k} \frac{1}{\left(1+r_{t+j}\right)}\right] P_{t+k}=0
$$

The above condition is also known as the transversality condition. Therefore, we obtain the price to be the present value of the dividends as: 


$$
P_{t}=\sum_{j=1}^{k}\left[\prod_{j=1}^{i} \frac{1}{\left(1+r_{t+j}\right)}\right] D_{t+j}
$$

The price $P_{t}$ only coincides with the future expected discounted dividend stream, called fundamental value of the asset $F_{t}$.

where:

$$
F_{t}=\sum_{j=1}^{k}\left[\prod_{j=1}^{i} \frac{1}{\left(1+r_{t+j}\right)}\right] D_{t+j}
$$

Then, Equation (2) becomes:

$$
P_{t}=F_{t}
$$

Without imposing the transversality condition, Equation (3b) is one of many possible prices that solve Equation (2). That is it is a specific solution of Equation (2). Therefore, the general solution becomes;

$$
P_{t}=F_{t}+B_{t}
$$

The equation says the asset price $P_{t}$ consists of a market fundamental $\left(F_{t}\right)$ and a bubble component $\left(B_{t}\right)$. The bubble component $\left(B_{t}\right)$ is a sub-martingale process (Diba \& Grossman, 1988) such that:

$$
E_{t}\left[B_{t+1}\right]=\frac{1}{\rho} B_{t}, \text { with } \frac{1}{\rho}>1
$$

Where: $\rho$ is the discount factor and is represented as:

$$
\rho=\frac{1}{1+r}
$$

Therefore, the expected bubble component becomes:

$$
E_{t}\left[B_{t+1}\right]=[1+r] B_{t}
$$

However, Campbell and Shiller (1988) provided the log-linear approximation of equation (1) as; 


$$
p_{t}=f_{t}+b_{t}
$$

The bubble process is explosive, with an autoregressive coefficient of $\left(\frac{1}{\rho}\right)$. In the absence of a bubble, the character of the fundamental component $f_{t}$, approximated by the character of the dividend and determines the stochastic behaviour of the price $\left(p_{t}\right)$, which is at most integrated of order one i.e $I(1)$. On the other hand, when explosive behaviour is observed in the price series $\left(p_{t}\right)$, it is taken as evidence of bubble occurrence in price (that is, if the price series is integrated of order greater than one). This is because the bubble component in Equation (4) and $(4 \mathrm{~d})$ is explosive and drives the stochastic behaviour of the prices when it becomes dominant. Therefore, empirical evidence of explosive behaviour in the asset price may be used to infer the existence of bubbles (Deng, et al., 2017) and forms the foundation of the GSADF (Phillips, et al.,2015) and SADF (Phillips, et al.,2011) tests.

\subsection{Results and Discussion}

This section presents results on the trend of nominal and real ASI, SADF and BSADF test results.

\subsection{Behaviour of Nominal and Real All-Share Index from 2010 to 2017}

The time evolution of nominal and real ASI expressed in 2009 basic prices was shown in Figure 1. Both the real and nominal ASI were normalised to 100 at the beginning of the sample period. As shown by the Figure, from 2012 to 2013, the market was stable with 2014 to 2016 being in persistent downward movement. This downward movement was attributed majorly to the heated election campaigns, political tension, and falling oil price in the international market. The dwindling NSE stock prices in 2016 could be attributed to the 2016 August recession. The market improved after the economy recovered from the recession in the second quarter of 2017 where the real growth changed from -1.4 per cent in the first quarter of 2017 to 0.78 per cent in the second quarter. In its reaction to the recovery, ASI recorded impressive improvement, particularly from March to July, ASI rose by 33.33 per 
cent from 25,516.34 on March 31, 2017, to 34,020.37 on July 21, 2017. However, the market recorded a slight decline after July 2017 and rebounded later as shown by the shaded region in Figure 1. This improvement was described as "seeming bubble" by MPC of CBN.

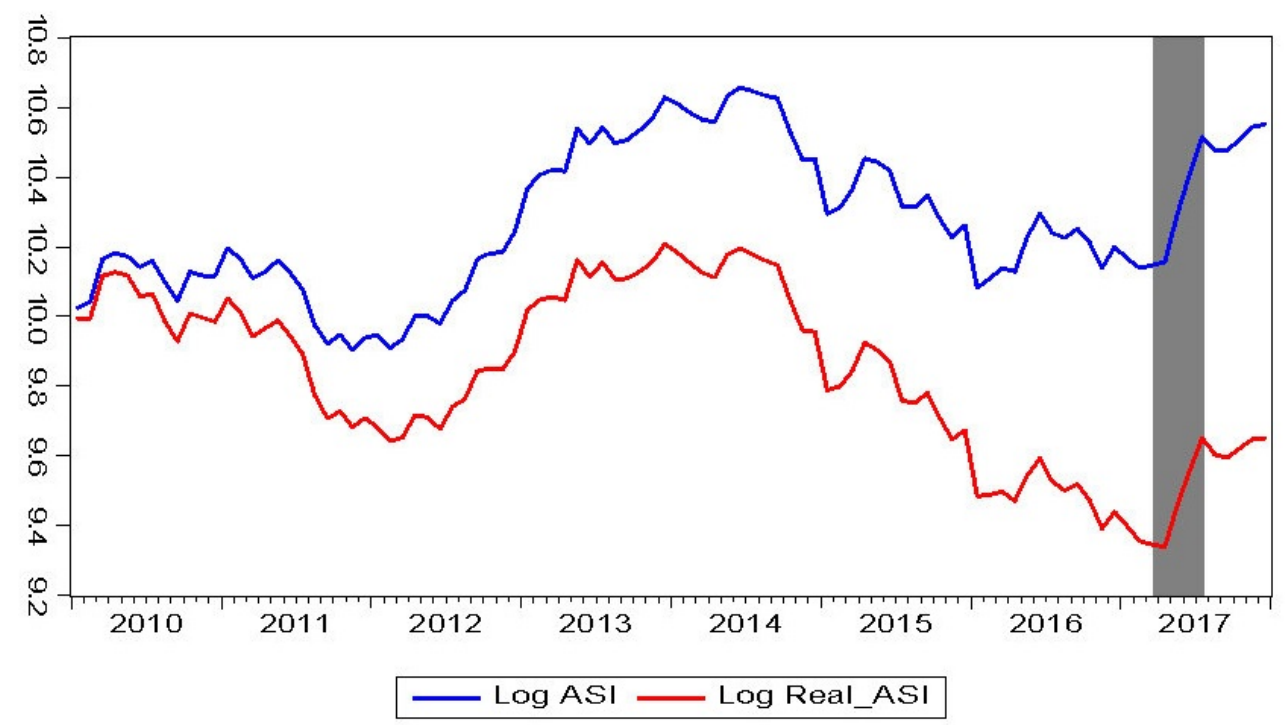

Figure 1: Behaviour of Nominal and Real All-Share Index from 2010M01 to 2017M12 $(2009=100)$

\subsection{Detecting a Bubble in the Nigerian Stock Exchange from 2010 to 2017}

Based on our objective of detecting the occurrence and date-stamping bubble, we implemented the Sup Augmented Dickey-Fuller (SADF) test and Table 1 reports the results. The results revealed no evidence of a bubble occurrence in the NSE during the study period (Table1). This was indicated by the SADF statistic of 0.317051 , that lied below critical values of $2.085976,1.347677$, and 0.932020 at 0.01 , 0.05 , as well as 0.1 levels of significance, respectively. This led to the acceptance of the null hypothesis of a unit root against the alternative of an explosive root. 
Table 1: Right Tail Dickey-Fuller Test for Bubbles in the Nigerian Stock

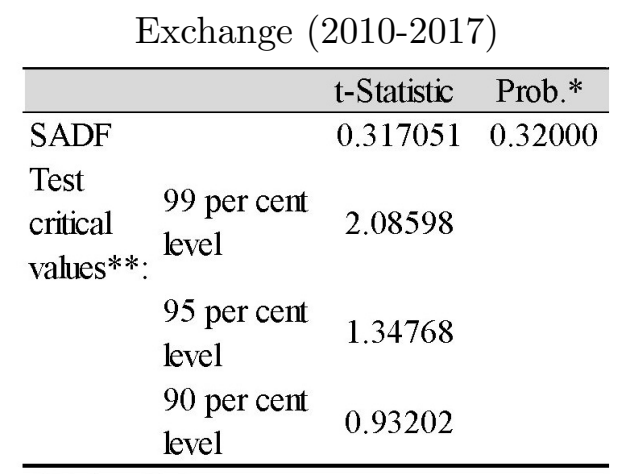

*Right-tailed test

**Critical values are based on a Monte

Carlo simulation (run with EVIews)

\subsection{Dating a Bubble in the Nigerian Stock Exchange from 2010 to 2017}

The results in Table 1 above reveal no evidence of a bubble occurrence in the NSE but for consistency and robustness check, we implemented BSADF date-stamping test and Figure 2 displays the results.

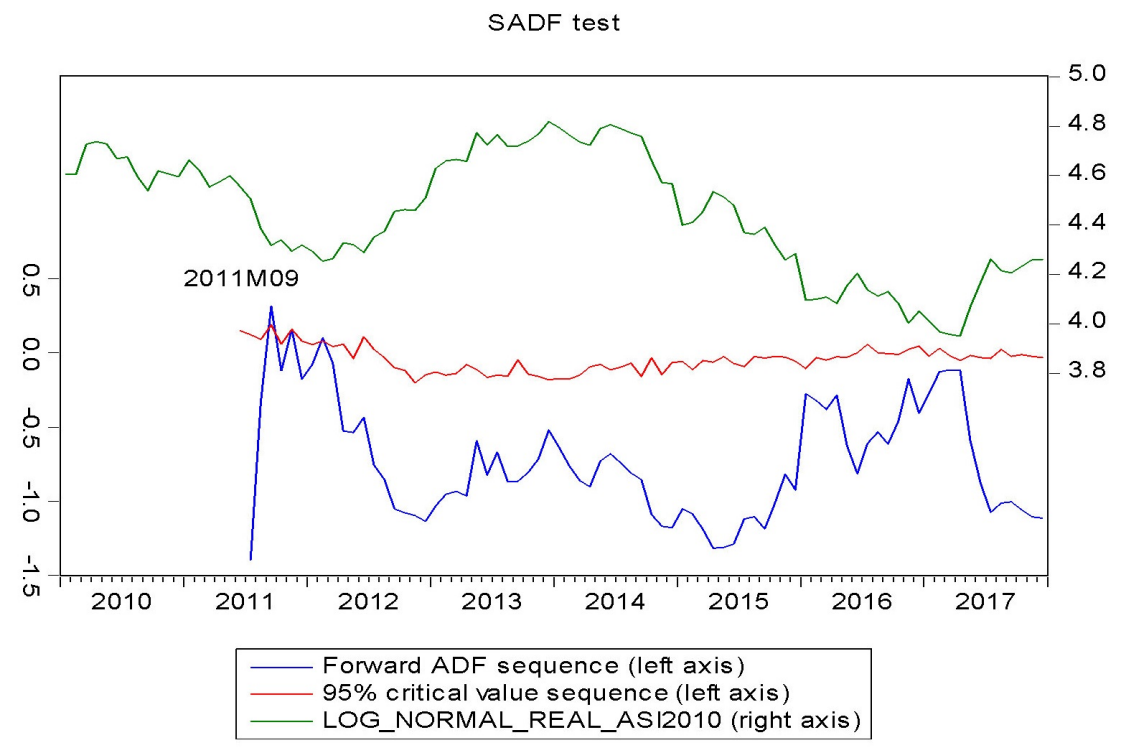

Figure 2: Dating a Bubble in Nigerian Stock Exchange from 2010 to 2017

The results show one occurrence of explosive behaviour in September 2011 at which the DF statistic lies above the critical values sequence line. However, this was not 
a bubble but a short deviation from trend because, based on the number of observations; the condition for the bubble must be, at least two months. Thus, the result from Figure 2 provides further support for the results in Table 1.

\subsection{Robustness Check of Sup Augmented Dickey-Fuller (SADF) Test}

Table 2 reports the Augmented Dickey-Fuller (ADF) and Right Tail ADF (RTADF) test statistics for logarithms of normalized real ASI (LNRASI) and the various critical values associated with each test for the full sample from January 2010 to December 2017. These tests are checks for the robustness of the SADF test. Following Diba and Grossman (1988), we applied the ADF test on the LNRASI to ascertain its effectiveness in bubbles detection. The result from Table 2 showed that the LNRASI is an $I(1)$ that is stationary after first difference. This means stocks prices in the NSE follow a random walk, had no memory and bubble was absent during the study period. Given that the standard unit root test cannot detect periodically collapsing bubbles (Evans, 1991). We, therefore, further applied Right Tail ADF (RTADF) test (see Table 2) which further revealed no evidence of the occurrence of a bubble, as the null hypothesis of unit root was accepted against the alternative of an explosive root.

Table 2: ADF and RTADF test statistic Results for LNRASI

\begin{tabular}{lcc}
\hline & ADF & RTADF \\
\hline Statistics & -8.56420 & -1.11065 \\
99 per cent & -3.50144 & 0.62155 \\
95 per cent & -2.892536 & -0.03022 \\
$p$-Value & 0.00000 & 0.29800 \\
\hline
\end{tabular}

Cuñado, et al. (2007), however, used a fractionally integrated autoregressive model to measure the existence of bubbles in S\&P500. They divided the sample period into two subsamples and estimated the long memory parameter (D) for each subsample, if it is greater than one, it reveals evidence for the existence of a bubble. Chang, et al. (2016) used Cuñado, et al., (2007) technique to check for 
the robustness of GASDF, a variant of SADF test and more effective when multiple episodes are suspected. Following Chang, et al. (2016) and estimating a fractionally-integrated autoregressive model of lag one, to test the robustness of the SADF test, we found no evidence of long memory in the normalised real ASI with the long memory parameter (D) of 0.094 (Table 3), which provided further evidence for the nonexistence of a bubble in the NSE.

Table 3: Long Memory Parameter Estimate from Fractionally Integrated

Autoregressive Model

\begin{tabular}{lrlrr}
\hline \hline \multicolumn{1}{c}{ Variable } & Coefficient & Std. Error & t-Statistic & Prob. \\
\hline \hline \multicolumn{1}{c}{ NOMRASI(-1) } & 0.993904 & 0.008821 & 112.6760 & 0.0000 \\
\multicolumn{1}{c}{ D } & 0.093557 & 0.086020 & 1.087628 & 0.2796 \\
\hline \hline R-squared & 0.942243 & Mean dependent var & & 87.63481 \\
Adjusted R-squared & 0.941622 & S.D. dependent var & 20.94571 \\
S.E. of regression & 5.060788 & Akaike info criterion & 6.102347 \\
Sum squared resid & 2381.877 & Schwarz criterion & 6.156112 \\
Log-likelihood & -287.8615 & Hannan-Quinn criteria. & & 6.124072 \\
Durbin-Watson stat & 1.961969 & & & \\
\hline \hline
\end{tabular}

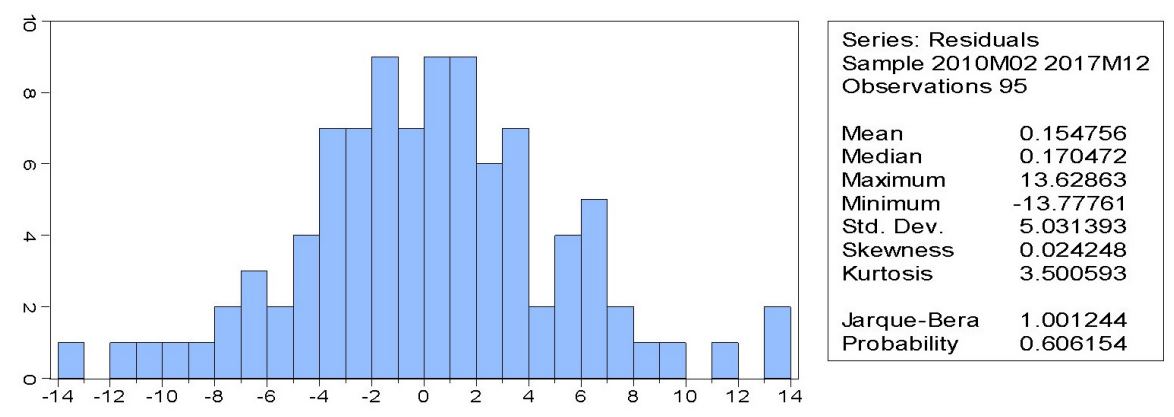

Figure 3: Test Normality of Residuals of the Fractionally Integrated Autoregressive Model

Similarly, the residuals from the estimated model were normally distributed (Figure 3) and had a serial correlation (Table 3).

In addition to Cuñado, et al. (2007) and Chang, et al. (2016), we further estimated the time-varying long memory parameter (D) to ascertain its behaviour over time. We used rolling regression with 19 observations in each regression with one step. From Figure 4, the long memory parameter (D) revolved around the closed interval of -0.85 to 0.5 . This result provided additional evidence against the existence 
of bubbles because, for the bubble, the parameter should be greater than one. Therefore, these results in Tables 1, 2, 3 and Figure 2, and 4 had provided empirical evidence that the behaviour of stocks prices in NSE was not driven by a bubble.

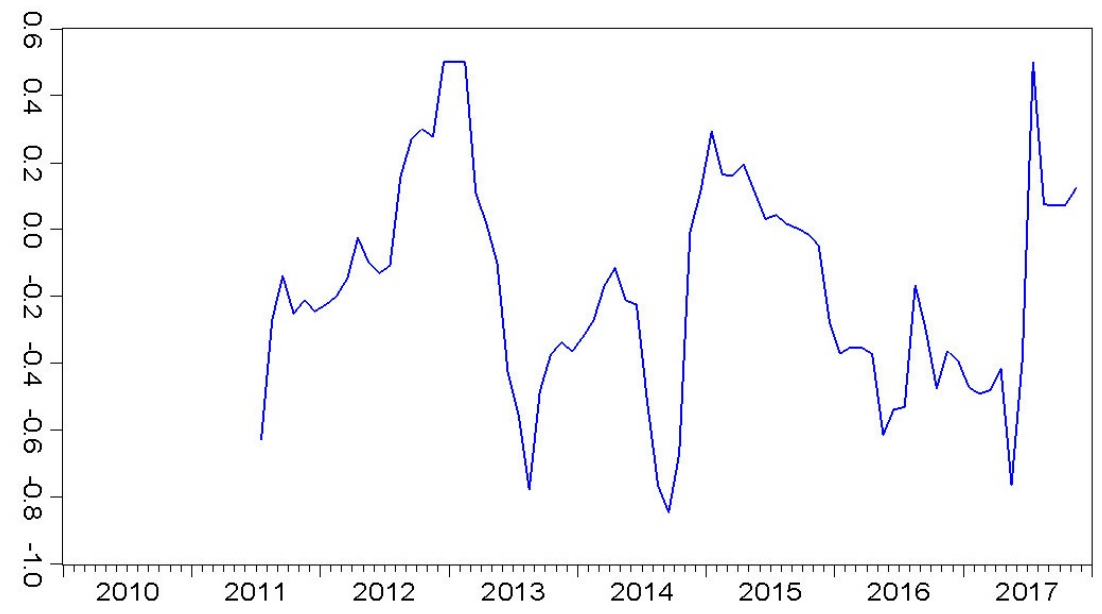

Figure 4: Time-Varying Long Memory Parameter (D)

\subsection{Conclusion}

This study provided an empirical analysis of the behaviour of stock prices in the NSE with a preference for bubble identification and date-stamping. We applied the SADF test, which is a rolling window right-sided ADF unit root test and is more appropriate when a single bubble is suspected. The application of SADF test on monthly data of real All-share index (ASI) from January 2010 to December 2017 showed no evidence for the existence of a bubble in the NSE. The observed explosive behaviour in September 2011, however, was not a bubble but short deviation from trend. This finding led to a deeper understanding of the behaviour of stock prices in NSE and the conclusion that NSE was not in a bubble regime, contrary to July 2017 MPC 's remark of seeming bubble in the NSE. In a situation like this, both the public and market may expect CBN to raise the MPR soon to push down the prices to their fundamental levels, thus may incorporate it into their current decision. This could reverse the price trend, resulting in a decline in market capitalisation, and an increase in the level of instability in the market, all in response to the false alarm. We, therefore, recommend a time-to-time bubble diagnostic 
check on the exchange so that symptoms of a bubble can be early detected and managed to avoid losses that may result from a bust.

\section{References}

Agu, C., \& Chukwuma-Agu, C. (2010). Shaky Pillars: Are Micro and Macroeconomic Fundamentals Enough to Explain the Strength of the Nigeria Stock Exchange? International Research Journal of Finance and Economics(40), $74-86$.

Almudhaf, F. (2017). Speculative Bubbles and Irrational Exuberance in African Stock Markets. Journal of Behavioral and Experimental Finance, 13, 28-32.

Balcilar, M., Guptab, R., Joosteb, C., \& Woharc, M. E. (2016). Periodically Collapsing Bubbles in the South African Stock Market. Research in International Business and Finance, 38, 191-201.

Blanchard, O. J. \& Watson, M. W. (1982). Bubbles, Rational Expectations, and Financial Markets. National Bureau of Economics Research (NBER) Eorking Paper No. 9115, 1 - 30.

Brunnermeie, M., S. R., \& Schnabel, I. (2018). Asset Price Bubbles and Systemic Risk. AFA 2018 Annual Meeting, Philadelphia; January 7, (pp. 1-29). Philadelphia.

Campell, J. Y., \& Shiller, R. J(1988). The Dividend-Price Ratio and Expectation of Future Dividends and Discount Factors. The Review of Financial Studies I (3), 195-228.http://www.jstor.org/stable/2961997

CBN. (2015). Central Bank of Nigeria 2015 Statistical Bulletin: Section A Final. Central Bank of Nigeria.

Chang, T., Aye, G. C., Gupta, R., \& Ranjbar, O. (2016). Test for Bubble in BRICS.

Chen, S.-W., Hsu, C.-S., \& Xie, Z. (2015). Are there Periodically Collapsing Bubbles in the Stock Markets? New International Evidence. Economic Modelling, 1-10.

Chukwuma-Agu, C., \& Agu, C. (2009). Behind the Crash: Analysis of the Roles of Macroeconomic Fundamentals and Market Bubbles in the Nigeria Stock Exchange. Paper Presented at the African Econometric Society Conference, Sheraton Hotel, Abuja; 8 - 10 July 2009, 1-33.

Cuñado, J., Gil-Alana, L. A., \& Gracia, F. P. (2007). Testing for Stock market Bubbles using Nonlinear Models and Fractional Integration. Applied Financial Economics, 17(16), 1313-1321, DOI:10.1080/09603100600970081. 
Deng, Y., Girardin, E., Joyeux, R., \& Shi, S. (2017). Did Bubbles Migrate from the Stock to the Housing Market in China between 2005 and 2010? Pacific Economic Review, Special Issues Article, 22(1), 276-292.

Diba, B. T., \& Grossman, H. I. (1988). The Theory of Rational Bubbles in Stock Prices. The Economic Journal, 98(392), 746-754.

Fama, E. F. (1965). Random Walks in Stock Market Prices. Reprinted from Financial Analysis Journal, 55-59.

Gwarzo, M. (2016). Policy Alternatives for Economic Recovery: The Role of Capital Market Regulator. Nigerian Journal of Securities Market (NJSM), $1(1), 6-16$.

Itamar, C., Katzke, N., \& Rangan, G. (2014). Date stamping historical oil price bubbles: 1876 - 2014. Stellenbosch Economic Working Papers: 20/14, A Working Paper of the Department of Economics and the Bureau for Economic Research at the University of Stellenbosch, South Africa, 1-17.

Krause, A. (2001). An Overview of Asset Pricing Models. School of Management, University of Bath.

Matthias, S. (1997). Rational Bubbles: theoretical basis, economic relevance, and empirical evidence with a special emphasis on the German stock market. In H. Albach, M. Beckmann, G. Feichtinger, W. Giith, W. Hildenbrand, W. Krelle, . . . R. Selten (Ed.), Lecture notes in economics and mathematical systems; 451. Berlin: Springer-Verlag Berlin Heidelberg.

McQueen, G., \& Thorley, S. (1994). Bubbles, Stock Returns, and Duration Dependence. The Journal of Financial and Quantitative Analysis, 29(3), 379-401.

Mike, O. A., \& Abraham, O. A. (2015). Macroeconomic Variables, Stock Market Bubble, Meltdown and Recovery: Evidence from Nigeria. Journal of Finance and Bank Management, 3(2), 25-34.

Njiforti, P., \& Chidiogo, A. (2010). Speculative bubble and The Nigerian Stock Exchange. Journal of Research in National Development, 8(2).

Nwidobie, B. M. (2015). Macroeconomic Determinants of Share Prices in the Nigerian Capital Market. Business $\&$ Entrepreneurship Journal, 4(2), 1-12.

Phillips, P. C., Shi, S., \& Yu, J. (2013). Testing for Multiple Bubbles: Historical Episodes of Exuberance and Collapse in the S\&P 500. Cowles Foundation Discussion Paper No. 1914, Cowles Foundation for Research in Economics; Yale University, New Haven, Connecticut. 
Phillips, P. C., Shi, S., \& Yu, J. (2015). Testing for Multiple Bubbles: Historical Episodes of Exuberance and Collapse in the S\&P 500. International Economic Review, 56(4), 1043-1078.

Phillips, P. C., Wu, Y., \& Yu, J. (2011). Explosive Behavior In the 1990s Nasdaq: When Did Exuberance Escalate Asset Values? International Economic Review: Research Collection School Of Economics., 201-226.

Porras, E. R. (2016). Bubbles and Contagion in Financial Markets: An Integrative View (First ed., Vol. 1). New York: Palgrave Macmillan.

Porras, E. R. (2017). Bubbles and Contagion in Financial Markets: Models and Mathematics (Vol. 2). Crinan Street, London, United Kingdom: Palgrave Macmillan.

Shiller, R. J. (2015). Irrational Exuberance (3rd Edition ed.). Princeton and Oxford: Princeton University Press: Princeton and Oxford.

Sornette, D. (2013). Dragon-kings and Predictions: Diagnostics and Forecasts for the World Financial Crisis. Department of Management, Technology, and Economics, ETH Zurich, Switzerland.

Yiu, M. S., Yu, J., \& Jin, L. (2012). Detecting Bubbles in Hong Kong Residential Property Market. Research Collection of School of Economics, Singapore Management University.

Zhoua, W.-X., \& Sornette, D. (2009). A case study of speculative financial bubbles in the South African stock Market 2003-2006. Physica A, 388, 869880 . 